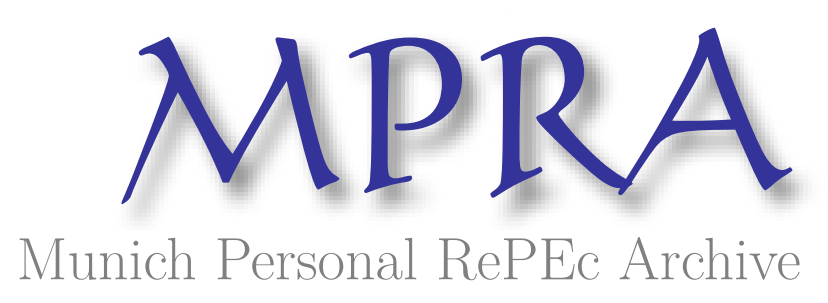

\title{
Sustainability of farms of natural persons in Bulgaria
}

Bachev, Hrabrin

Institute of Agricultural Economics, Sofia

January 2017

Online at https://mpra.ub.uni-muenchen.de/76899/

MPRA Paper No. 76899, posted 18 Feb 2017 14:16 UTC 


\title{
Sustainability of Farms of Natural Persons in Bulgaria \\ Hrabrin Bachev ${ }^{1}$
}

\begin{abstract}
The issue of adequate assessment of socio-economic and ecological sustainability of divers agricultural holdings is among most topical academic and practical problems. It is particularly important for smallholder farms accounting for the majority of all farms in the globe. In Bulgaria unregistered farms of Natural Persons account for almost $98 \%$ of all farms in the country, cultivate a third of all farmlands, graze $85 \%$ of cows, $90 \%$ of sheep, and around a third of pigs, and employ almost $93 \%$ of workforce in the sectors. This article applies a holistic framework and assesses sustainability of farms of Natural Persons in Bulgaria during current stage of EU CAP implementation. Initially a new governance aspect of farm sustainability is justified and method outlined. After that assessment is made of integral, governance, economic, social, environmental sustainability of farms of Natural Persons of different size, specialization, and location, and comparative sustainability to other type of farms. Finally, directions for further research and amelioration of sustainability assessment practices are suggested. Overall sustainability of Natural Persons in the country is at a good level, with superior levels for environmental and social sustainability, close to the low level governance sustainability, and inferior economic sustainability. Comparative sustainability of holdings is lower than other juridical type. There are great variations in sustainability levels of farms of different kind and location. Share of Natural Persons with good and high sustainability is smaller than other categories of farms and majority of Natural Persons have no comparative advantages in terms of sustainability, and in a middle term will cease to exist.
\end{abstract}

Key words: smallholders sustainability, governance, economic, social, environmental aspects, Bulgaria

\footnotetext{
${ }^{1}$ Professor, Institute of Agricultural Economics, Sofia, Bulgaria, e-mail: hbachev@yahoo.com
} 


\section{Introduction}

The issue of adequate assessment of diverse aspects of sustainability of farms of different type is among the most topical academic and practical matters - for managers of agri-business enterprises, professional associations of agricultural producers, policy-makers, interests groups, researchers, and public at large (Andreoli and Tellarini, 2000; Bachev, 2005, 2010, 2016; Bachev and Petters, 2005; Bastianoni et al., 2001; Brklacich. and Smith; Csaki et al., 2008; Davidova, 2014; Diazabakana et al., 2014; EC, 2001; FAO, 2013; Fuentes, 2004; Häni et al., 2006 ; OECD, 2001; Rigby et al., 2001; Sauvenier et al., 2005; UN, 2015). For instance at current stage of European Union (EU) Common Agricultural Policy (CAP) implementation in individual member states are very important following questions: how to assess sustainability levels of different governance structures - farming enterprises on different type; to what extent various mechanisms and instruments of Common policies of the Union affect sustainability of different farms; and how to improve sustainability of holdings through effective changes in management strategies and forms of public intervention in the sector. Nevertheless, in Bulgaria like in other countries from Central and East Europe practically there are no or a few comprehensive studies on sustainability of farms during reformed EU CAP implementation.

During post-communist transition and EU integration of Bulgarian agriculture there has evolved a specific governance structure consisting of numerous "unregistered" farms of Natural (Physical) Persons, and a few registered agri-business enterprises of Sole Traders, Companies (Corporation), and Cooperatives (Bachev and Tsuji, 2001; Bachev \& Nanseki, 2008). Assessing absolute and comparative sustainability of all these farms is very important at current stage of development of strong competition at domestic and international markets, fundamental institutional modernization in past years (introduction of Acquis Communautaire, EU quality, safety, labor, environmental, animal welfare, etc. standards, reforming Common agricultural, environmental etc. policies, etc.), global climate change, etc. All these issues are particularly important in respect to a specific type of agricultural holdings in the country - unregistered farms of Natural Persons. The latter account for almost $98 \%$ of all farms in the country, cultivate a third of all farmlands, graze $85 \%$ of cows, $90 \%$ of sheep, and around a third of pigs, and employ almost $93 \%$ of workforce in the sectors (MAF, 2012).

In academic publications, official documents and agricultural practices is already common, that besides "pure" economic farms sustainability has broader social and environmental 
aspects ("pillars"), which are equally important and have to be accounted for. However, critical for farm' sustainability and efficiency "governance" functions of the farm and associated “transaction" costs are largely ignored (Bachev, 2004, 2005). Nevertheless, frequently comparative governance efficiency (potential to minimize transaction costs and maximize transacting benefits) and capacity for adaptation (adaptability to market, institutional and natural environment) (pre) determine the overall sustainability of a farm despite its productivity, social responsibility or nature conservation of activity.

Furthermore, most of recommended frameworks for sustainability assessment employ "universal" ("institution free") approach for "faceless" farms and "anonymous" environment, without taking into consideration personal characteristics (capability, preferences, risk-aversion) of farm owner(s) and farm' specificity (type, resource endowment, specialization, stage of development), comparative efficiency and sustainability of other available (alternative) governing structures, and specific socio-economic and natural environment (competition, institutional support and restrictions, environmental challenges and risks), in which individual holding functions (Bachev \& Petters, 2005). In such "nirvana” approach not real (or feasible) alternative organizations are used as a criterion but unrealistic (ideal) modes such as model of farming and development in other (developed, EU, neighboring) countries or conditions (controlled, experimental); presumptions for universal and well-defined and enforced rights and standards; perfectly working agrarian (government) administration; situation without public interventions, etc. In fact, framework of assessment is to take into account real socio-economic, institutional and natural environment, in which a farm functions and evolves - specific "Bulgarian" model of EU CAP implementation, social preferences and demands, technologies dissemination, climate changes affecting agriculture, etc.

Finally, most of existing frameworks are not hierarchical and lack systemic organization of aspects and components of farm's sustainability, which (pre)determine arbitrary selection of assessment indicators (Sauvenier et al., 2005). Usually, applied system are either too simplified (limited number of "major" indicators), or unilateral ("pure" economic aspects, "pure" ecological" aspects), or too complicated and impossible to use by farmers and managerial bodies (Hayati et al., 2010).

This article applies a holistic framework for assessing sustainability of Bulgarian farms, based on interdisciplinary theories of New Institutional Economics and Agrarian Sustainability, 
and evaluates absolute and comparative sustainability of holdings of Natural Persons with different size, product specialization, and ecological and geographical location.

\section{Methodology}

Studying out of farm as a governance structure let properly understand efficiency and sustainability of economic organizations in agriculture (Bachev, 2004, 2005). In a long-term no economic organization would exist if it were not efficient, otherwise it will be replaced by more efficient arrangement. Therefore, the problem of assessment of sustainability of farms is directly related to estimation of level of governance, economic, social and environmental efficiency of farms.

In Traditional Economics the farm is presented as a "production structure" and analyses of efficiency is restricted to "optimization of technological factors" ("production" costs) according to marginal rule. This approach fails to explain a high sustainability and coexistence of numerous farms of different type (semi-market holdings, cooperatives, small commercial farms, large agri-firms) with great variation in "efficiency levels" in Bulgaria (and other Central and East European countries) during last two and a half decades.

In real economy with positive transition costs and institutions "taht matter" farms and other agrarian organizations are not only production but major governance structures - modes for governing of activity and transactions (Bachev, 2004). Therefore, sustainability of diverse type of farming structures cannot be properly understood and estimated without analyzing their comparative production and governance potential. Following New Institutional Economics logic (Williamson, 1996) governance efficiency characterizes comparative potential of a particular form (type of farm) to minimize transaction costs and increase transaction benefits in relation to another feasible organization in specific socio-economic and natural environment.

Hence a farm will be efficient (sustainable) if it manages all activities and transactions in the most economical for owner(s) way. If a farm does not govern transactions (activity) effectively, it will be unsustainable since it will have high costs and difficulties for functioning in specific environment (possibilities and restrictions) comparing to another feasible (alternative) organization. In that case, there will be strong incentives for exploring existing potential (adapting to a sustainable state) through reduction or enlargement of farm size, or via reorganization or liquidation of farm. Consequently, some of following will take place - 
alternative farm or non-farm application of available resources; or farm expansion through employment of additional resources; or trade instead of internal use of owned land and labor; or taking over by or merger with another farm of business (Bachev \& Petters, 2005).

Modes of governance and acceptable (for owners, community, society) net benefits will vary according to personal preference of individual agents, entrepreneurial capability and experience, risk aversion, opportunity costs of owned resources, institutional restrictions and norms, pressure and opportunities of specific environment (competition, demand, cooperation, support, climate change), etc.

Major types of farm activities (and transactions) subject of management are: supply and governance of labor resources; supply and governance of land and natural resources; supply and governance of material inputs; supply and governance of innovations; supply and governance of finance; and governance of marketing of products and services, etc. Sustainability assessment is to include comparative efficiency of governance of each of these activities of a farm in specific institutional, economic, social and natural environment in which that holding functions and evolves. If it is detected a lack of acceptable efficiency (significant costs and difficulties, insufficient benefits) in relation to feasible alternative(s), then farm is to be considered as lowsustainable or non-sustainable.

Next, it has to be evaluated the farm's potential for adaptation to constantly evolving market, economic, institutional, social and natural environment through effective changes in governing forms, size, production structure, technologies, and behavior. If the farm does not have potential to stay at or adapt to new more sustainable level(s) it will diminish its comparative advantages and sustainability, and (eventually) will be liquidated or transformed into another type of organization. For instance, if a farm faces enormous difficulties meeting institutional norms and restrictions (imposed and enforced by EU new standards for quality, safety, environmental protection, animal welfare); higher social norms and requirements (for working conditions, income level, welfare of farmers and farm households; new demands of rural communities), and taking advantage of institutional opportunities (access to public support programs); or it has serious problems supplying managerial capital (as it is in a one-person farm when an aged farmer does not have a successor wishing or capable of taking over the business), or supply of farmland (big demand of farmland by other entrepreneurs or for non-agricultural use), or funding activities (insufficient own finance, impossibility for coalition, selling equity or buying credit), or 
marketing output and services (changing market demand for certain products or needs of coowners and buyers, a strong competition with imported products); or it is unable to adapt to existing environmental challenges and risks (warning, extreme climate, soil acidification, waters pollution, etc.), then it will not be sustainable despite the high historical or current efficiency. Therefore, adaptability of farm characterizes to the greatest extent farm sustainability and has to be used as a main criteria and indicator for sustainability assessment ${ }^{2}$.

We have proved that definition farm sustainability has to be based on the "literal" meaning of that term and perceived as a system characteristics and "ability to continue through time" (Bachev, 2005). ". It has to characterize all major aspects of farming enterprise activity, which is to be managerially sustainable, and economically sustainable, and socially sustainable, and environmentally sustainable. Therefore, farm sustainability characterizes the ability (internal potential, incentives, comparative advantages, importance, efficiency) of a particular farm to maintain its governance, economic, social and ecological functions in a long-term in the specific socio-economic and natural environment in which it functions and evolves (Bachev, 2016). Depending on combination of all four dimensions, sustainability of a particular farm could be high, good, unsatisfactory, or farm is unsustainable.

Farm sustainability has for aspects ("pillars"), which are equally important and always have to be taken into account:

- governance sustainability - to have good or high absolute and comparative efficiency in organization and management of activity and (internal and external) relations of the farm, and a high adaptability to evolving socio-economic and natural environment, according to specific preferences (type of enterprise, character of production, long-term goals, etc.) and capabilities (education, experience, available resources, connections, power positions, etc.) of owners of the enterprise;

economic sustainability - to have good or high productivity of deployed natural, labor, material and financial resources, sufficient ("acceptable") economic efficiency and competitiveness, and needed financial stability of activity;

- $\quad$ social sustainability - to have good or high social responsibility in regard to farmers, hired labor, other agents, communities, and consumers, and contribute to preservation of

\footnotetext{
${ }^{2}$ Our suggestion to use adaptability as a criteria and indicator for sustainability has been already incorporated in one of the most comprehensive System for Assessing Sustainability of Agriculture Systems in Belgium - SAFE (Sauvenier et al., 2005).
} 
agrarian resources and traditions, amelioration of wellbeing and life style of farm households, and development of rural communities and the society as a whole;

$$
\text { environmental sustainability - to have good or high eco-efficiency of activity, }
$$

which is to associated with necessary conservation, recovery and improvement of components of natural environment (landscape, lands, waters, biodiversity, atmosphere, climate, ecosystem services, etc.) and the nature as a whole, respecting welfare of farm and wild animals, etc.

This framework for assessing sustainability of Bulgarian farms has to include hierarchical system of 12 Principles, 21 Criteria, 45 Indicators and Reference values (Figure 1). That system let specify the most adequate indicators for the specific Bulgarian conditions taking into account all aspects of farm sustainability. Specific content, justification, modes of selection, calculation and integration of all elements of that framework are presented in details in another publication (Bachev, 2016).

\section{Figure 1. Hierarchical Framework for Assessing Sustainability of Bulgarian Farms *}

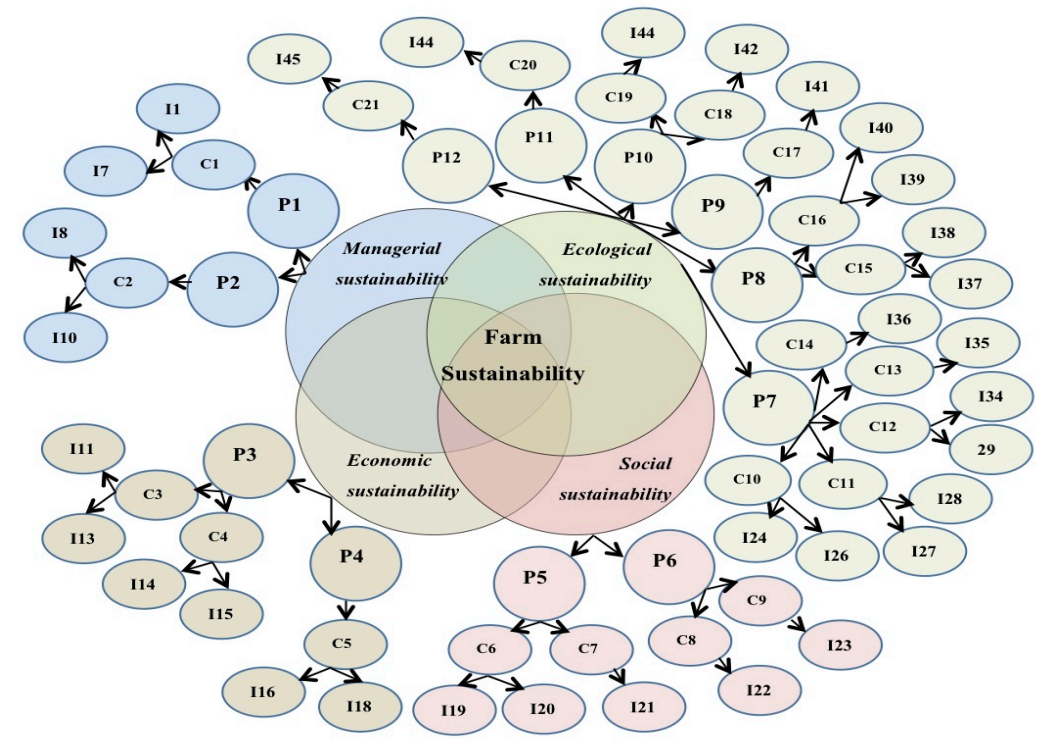

*P - Principle, C - Criterion, I - Indicator Source: author

Assessment of sustainability of farms in the country is based on a 2016 survey with the managers of "representative" market-oriented farms of different type. The survey was carried out with assistance of National Agricultural Advisory Service and major agricultural producers associations, which identified "typical" holdings of different type and location. 
Assessment of sustainability level of individual farms is based on first-hand information from the managers of "representative" holdings collected in summer of 2016. The survey with farm managers included 152 of Natural Persons, which comprise around 0,2\% of all registered under 1999 Regulation No 3 for Creation and Maintaining a Registry of Agricultural Producers in Bulgaria (MAF, 2015). The structure and importance of surveyed farms of different kind and location approximately corresponds to the real structure of market-oriented holdings of Natural Persons in the country.

Sustainability of individual farms is based on the estimates of farm managers for each Indicator in four qualitative levels: "High/Higher or Better that the Average in the Sector/Region", "Similar/Good", "Low/Lower or Worse than the Average in the Sector/Region", "Negative/Unsatisfactory/Unacceptable". That approach is the only feasible to get necessary data since the level of most governance and social indicators is practically "known" only by farm managers (e.g. satisfaction of activity, acceptable income, available alternative for supply of inputs etc.). Furthermore, our pilot study has proven that the majority of farm manager are fwell familiar with comparative production, economic and financial indicators of their farms in relation to the industry average, as well as with most available environmental indicators. On the other hand, precise data for certain ecological indicators on farm levels are not available in Bulgaria and they can only be gathered through costly laboratory tests.

The next step has been to transform the qualitative estimates into Sustainability Index for each indicator $\left(\mathrm{SI}_{(\mathrm{i})}\right)$. Following scales have been used: 1 for "High", 0,66 for "Good or Average", 0,33 for "Low", and 0 for "Unsatisfactory or Unacceptable".

Major market-oriented type of farms in the country are Natural Persons, Sole Traders, Cooperatives, and Companies, and comparative sustainability of Natural Persons is evaluated in relations to other juridical type. For classification of farms according to production specialization, ecological and administrative locations the official typology for farming holdings in the country is used. In addition, every manager self-determined his/her farming enterprises as Predominately for Subsistence, rather Small, Middle size or Big for the sector, and located mainly in Plain, Plain-mountainous or Mountainous region. The latter approach guarantees an adequate assessment since farms' managers are well aware of the specificity and comparative characteristics of their holdings in relations to others in the region and (sub)sector. 
For integral assessment of sustainability of a farm for each Criterion, Principle, Aspect and Overall level, equal weights are used for each Principle in a particular Aspect, and for each Criterion in a particular Principle, and for each Indicator in a particular Criterion. Individual Criteria (SI(c)), Principle (SI(p)), Aspect (SI(a)), and Integral Sustainability Index (SI(o)) are calculated by formulas:

$$
\begin{array}{lr}
\mathrm{SI}(\mathrm{c})=\sum \mathrm{SI}(\mathrm{i}) / \mathrm{n} & \mathrm{n}-\text { number of Indicators in a particular Criterion } \\
\mathrm{SI}(\mathrm{p})=\sum \mathrm{SI}(\mathrm{c}) / \mathrm{n} & \mathrm{n} \text { - number of Criteria in a particular Principle } \\
\mathrm{SI}(\mathrm{a})=\sum \mathrm{SI}(\mathrm{p}) / \mathrm{n} & \mathrm{n} \text { - number of Principles in a particular Aspect } \\
\mathrm{SI}(\mathrm{o})=\sum \text { ИУ }(\mathrm{a}) / 4 &
\end{array}
$$

For interpretation of quantitative levels following sustainability levels of farms are distinguished by a Panel of Experts: "High" - range between 0,84 and 1, "Good" - range between 0,5 to 0,82 , "Low" - range 0,22 to 0,49 , and "Non-sustainable" - between 0 and 0,2.

The overall and particular (Aspect, Principle, Criterion, Indicator) sustainability of farms of a specific kind and location is an arithmetic average of the Indexes of individual holdings in that particular group.

\section{Results}

Multi-indicators assessment of sustainability level of farms of Natural Persons indicates, that the Integral Sustainability Index is 0,53 , which represents a good level of sustainability of holdings (Figure 2). With the highest levels are Indexes of Environmental $(0,6)$ and Social $(0,55)$ Sustainability of these enterprises, while Index of Governance $(0,51)$ Sustainability is at the border with a low level. What is more, Natural Persons are with a low economic sustainability, which demonstrates that improvement of the latter one is critical for maintaining the overall sustainability of farms of that type. 
Figure 2. Indexes of Integral, Governance, Economics, Social and Environmental Sustainability of Farms of Natural Persons in Bulgaria

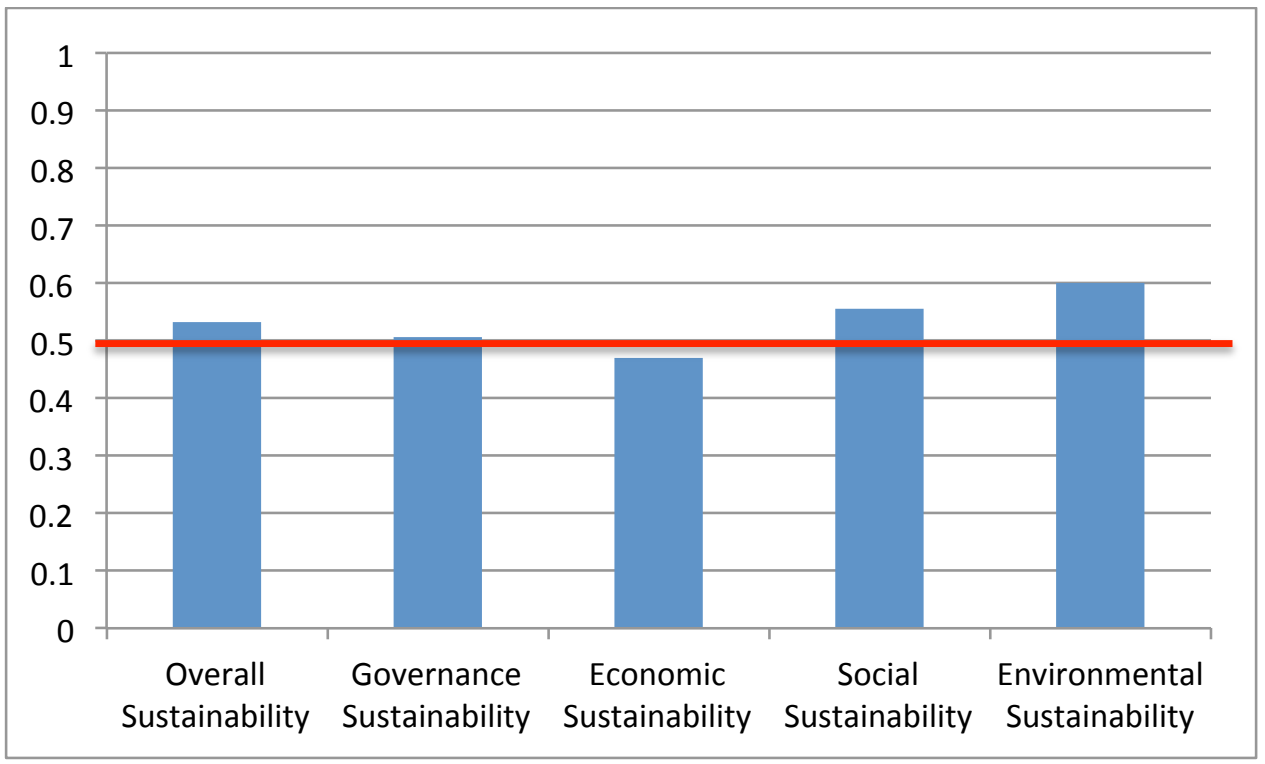

Source: survey with managers of farms, July 2016

Comparative sustainability of farms of Natural Persons is lower than the average sustainability of farms in the country and levels of other juridical type of enterprises in agriculture (Figure 3). Sustainability level of Natural Persons only approximates the level of Sole Traders and it is much inferior from Companies and Cooperatives. However, while governance and economic sustainability of Natural Persons is lower from all categories of enterprises, in social and environmental aspects it is superior to Sole Traders, and in environmental close to cooperative farms. 
Figure 3. Sustainability of Farms with Different Juridical Type in Bulgaria

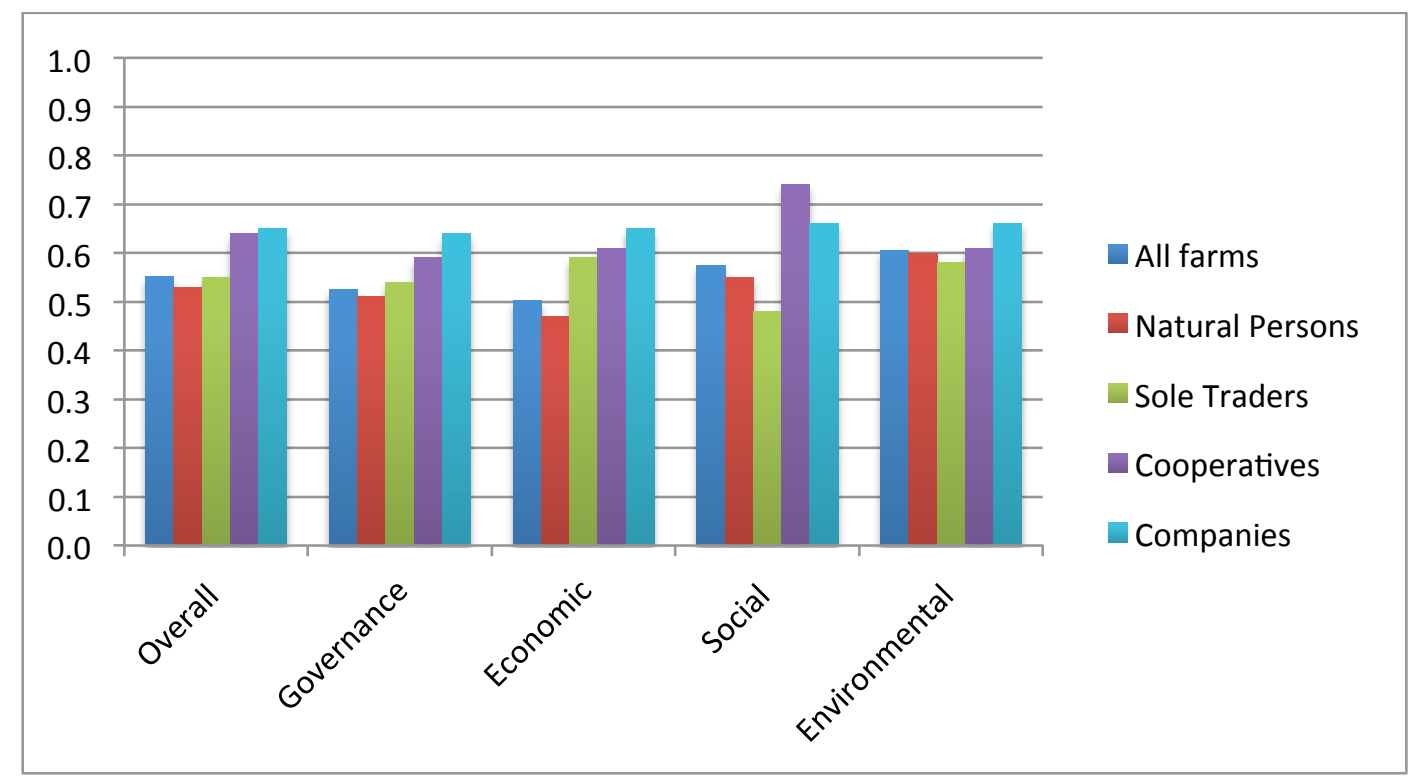

Source: survey with managers of farms, July 2016

Analysis of individual Indexes for major sustainability Principles, Criteria and Indicators let identify components contributing to sustainability levels for diverse aspects of sustainability of holdings of Natural Persons. For instance, economic sustainability of farms is low because of the fact that the Index of Financial Stability $(0,47)$ of these enterprises holdings is low (Figure 4). Similarly, the inferior level of the Index of Governance Efficiency $(0,49)$ is responsible for marginal level of governance sustainability of these enterprises. It is also clear that despite that the overall environmental sustainability of holdings is relatively high, the Index of Respecting Animal-Welfare Principle $(0,43)$ is low, and the Index of Preservation of Preservation of Agricultural Lands marginal $(0,52)$. Improvement of the latter two is critical for maintaining the achieved level. 
Figure 4. Indexes of Sustainability for Major Principles for Governance, Economics, Social and Environmental Sustainability of Natural Persons in Bulgaria

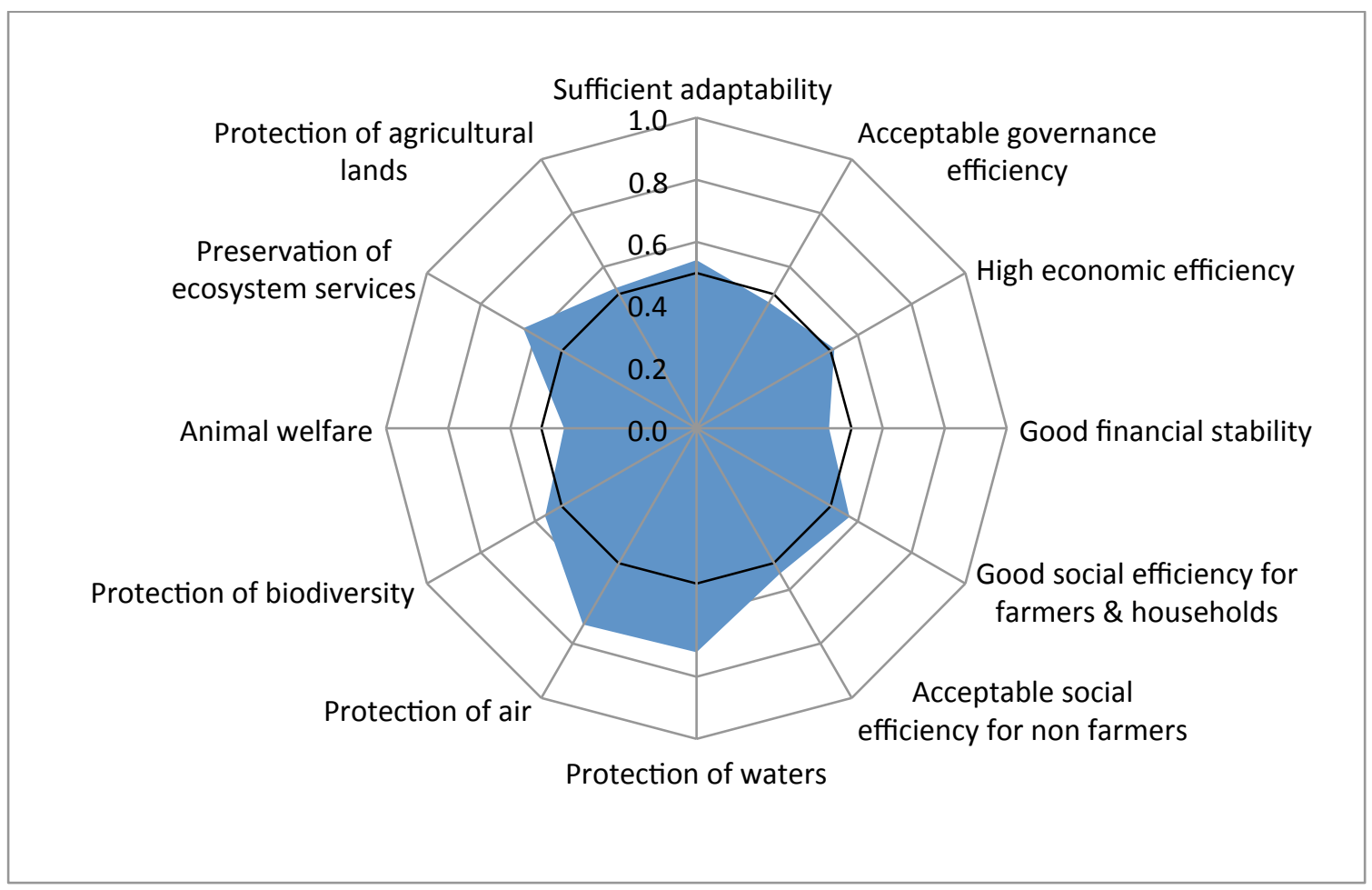

Source: survey with managers of farms, July 2016

In depth analysis for individual Criteria and Indicators further specifies the elements, which enhance or reduce sustainability level of farms. For instance, insufficient Financial Stability is determined by low Financial Capability $(0,43)$, which is predetermined by unsatisfactory Profitability of Own Capital $(0,36)$, Overall Liquidity $(0,44)$, and Financial Autonomy $(0,48)$ of enterprises (Figure 5 and Figure 6). 
Figure 5. Level of Sustainability for Individual Criteria for Governance, Economics, Social and Environmental Sustainability of Natural Persons in Bulgaria

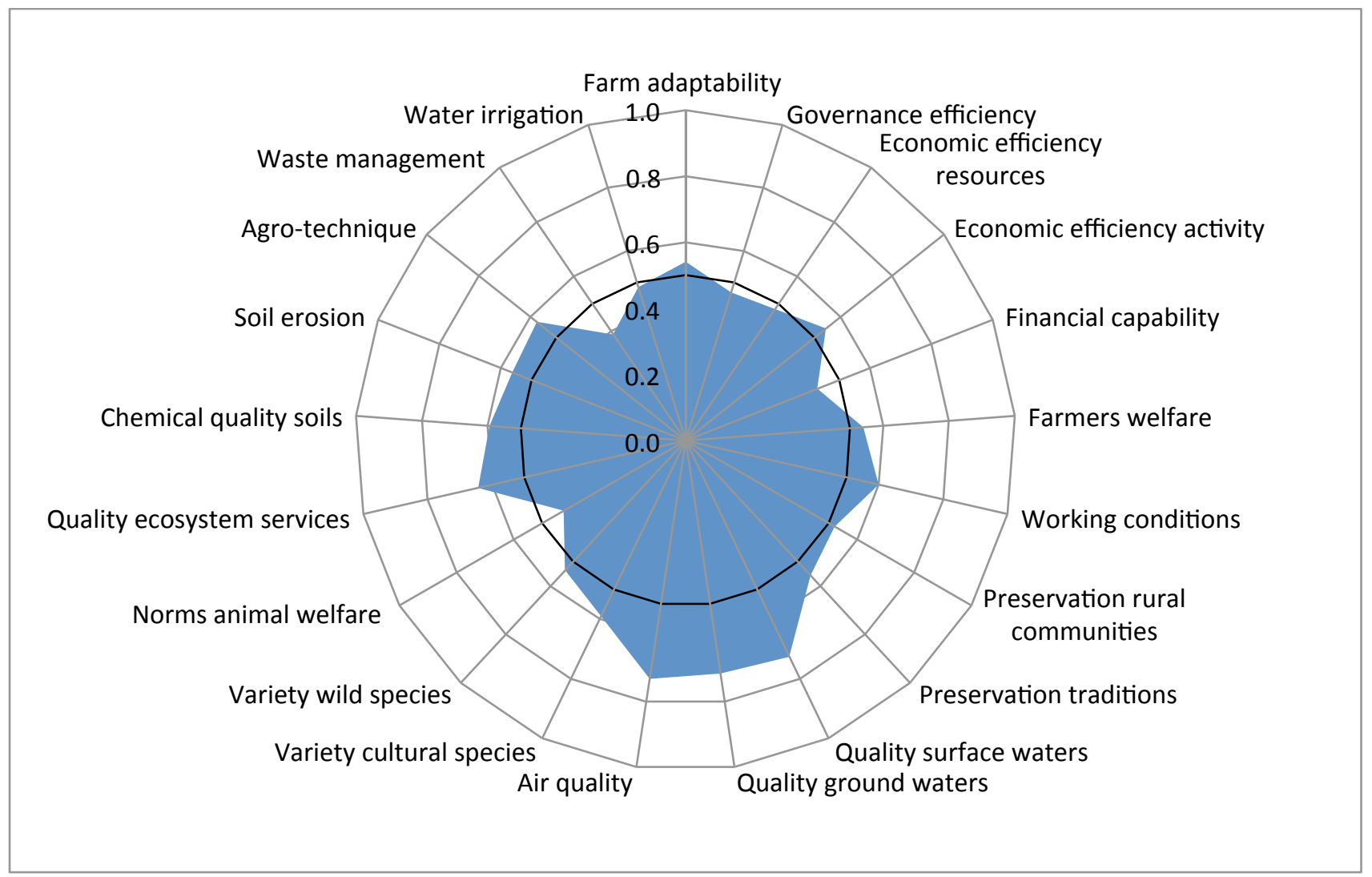

Source: survey with managers of farms, July 2016 
Figure 6. Indicators* of Assessing Sustainability of Enterprises of Natural Persons

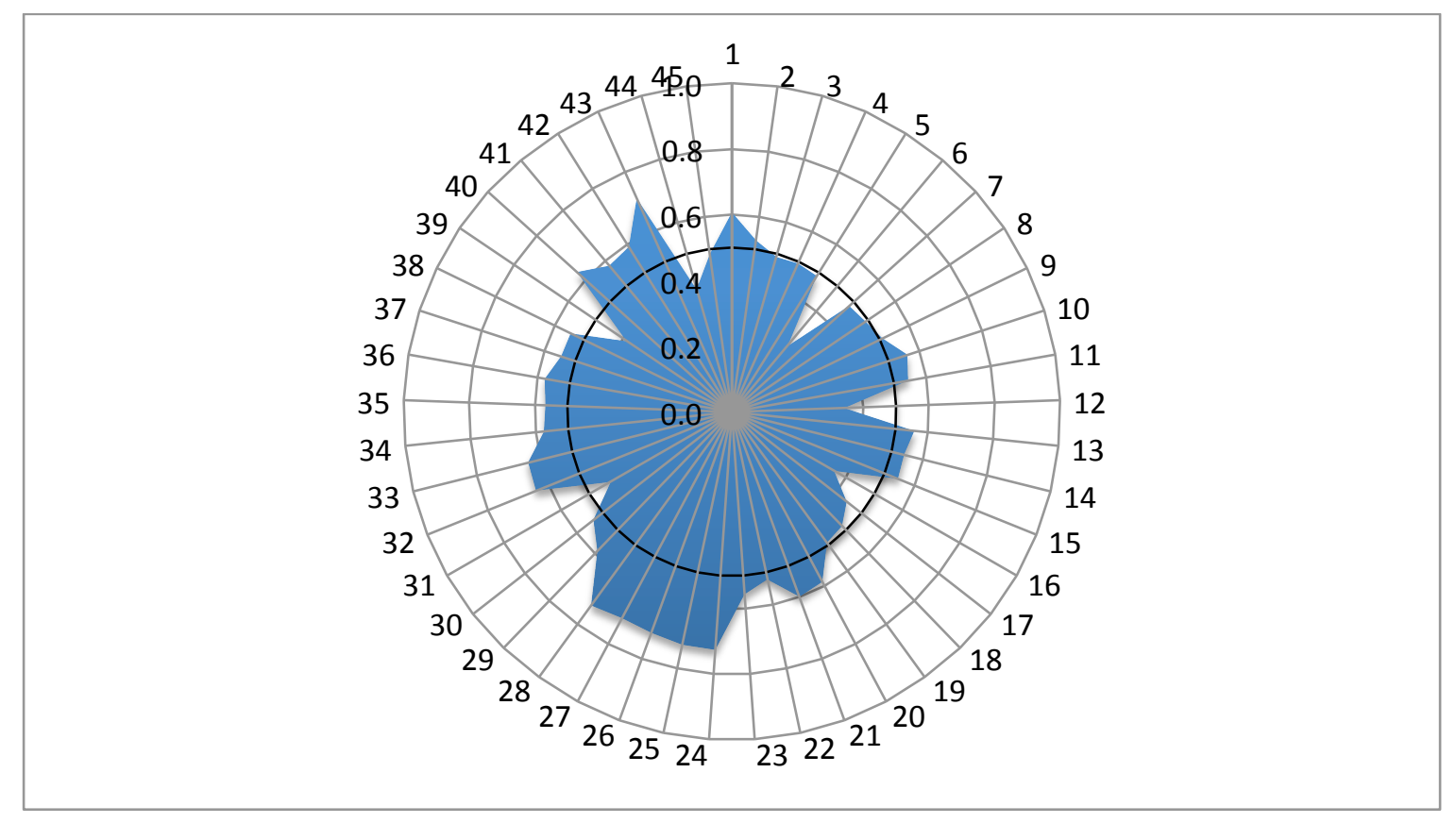

*1-Level of Adaptability to Market Environment; 2-Level of Adaptability to Institutional Environment; 3Level of Adaptability to Natural Environment; 4-Comparative Efficiency of Supply and Governance of Labor Resources; I5-Comparative Efficiency of Supply and Governance of Natural Recourses; I6-Comparative Efficiency of Supply and Governance of Short-term inputs; I7-Comparative Efficiency of Supply and Governance of Long-term Inputs; I8-Comparative Efficiency of Supply and Governance of Innovation; I9-Comparative Efficiency of Supply and Governance of Finance; I10-Comparative Efficiency of Governance of Marketing of Products and Services; I11Land productivity; I12-Livestock Productivity; I13-Level of Labor productivity; I14-Rate of Profitability of Production; I15-Income of Enterprise; I16-Rate of Profitability of Own Capital; I-17-Overall Liquidity; I18-Financial Autonomy; I19-Income per Farm-household Member; I-20-Satisfaction of Activity; I21-Compliance with Working Conditions Standards; I22-Contribution to Preservation of Rural Communities; I23-Contribution to Preservation of Traditions; I24-Nitrate Content in Surface Waters; I25-Pesticide Content in Surface Waters; I26-Nitrate Content in Ground Waters; I27-Pesticide Content in Ground Waters; I28-Extent of Air Pollution; I-29-Number of Cultural Species; I30-Number of Wild Species; I31-Extent of Respecting Animal Welfare; I32-Extent of Preservation of Quality of Ecosystem Services; I33-Soil Organic Content; I34-Soil Acidity; I35-Soil Soltification; I36-Extent of Wind Erosion; I37-Extent of Water Erosion; I38-Crop Rotation; I39-Number of Livestock per ha of Farmland; I40Norm of Nitrogen Fertilization; I41-Norm of Phosphorus Fertilization; I42-Norm of Potassium Fertilization; I43Extent of Application of Good Agricultural Practices; I44-Type of Manure Storage; I45-Irrigation Rate

Source: survey with managers of farms, July 2016

Most sustainability indicators of Natural Persons are low and lead to a decrease in sustainability for individual aspects and the overall level. In governance aspect of sustainability of these holdings are inferior the Level of Adaptability to Natural Environment $(0,49)$, and Comparative Efficiency of Supply and Governance of Labor Resources $(0,49)$, Natural Resources 
$(0,49)$, Long-term Inputs $(0,49)$, and Innovations $(0,49)$, and extremely low the Comparative Efficiency of Supply and Governance of Short-term Inputs $(0,26)$.

In economics aspect sustainability of Natural Persons is particularly low in respect to Livestock Productivity (0,34), Rate of Profitability of Own Capital (0,36), Overall Liquidity $(0,44)$, and Financial Autonomy $(0,48)$. In social aspect sustainability of these holdings is only low in relation to Income per Farm-household Member $(0,49)$, while in environmental plan in respect to complying with norms for Number of Livestock per ha of Farmland $(0,43)$, Type of Manure Storage (0,39), Extent of Respecting Animal Welfare $(0,43)$, and Irrigation Rate $(0,49)$. In all these directions adequate measures have to be taken by managers of farms and state authority in order to improve aspect and overall sustainability of Natural Persons.

At the same time, a number of indicators for environmental sustainability of Natural Persons are with relatively high positive positions within a good level: Nitrate and Pesticides Content in Surface and Ground Waters, Extent of Air Pollution, and Extent of Application of Good Agricultural Practices. All these advantages of Natural Persons are to be maintained and enhanced, while other indicators for eco-efficiency increased in order to preserve and increase aspect and overall sustainability of these types of farms.

Low levels of indicators identify the specific areas for improvement of sustainability of farms through adequate changes in management strategy of enterprises and/or public policies for farming structures. For instance, despite that the overall Adaptability of Farms is relatively high $(0,54)$, the Adaptability of Farms to Changes in Natural Environment (climate, extreme events, etc.) is low $(0,49)$. Therefore, effective measures are to be undertaken to improve the latter type of adaptability through education, training, information, amelioration of agro-techniques, structure of production and varieties, technological and organizational innovations, etc.

On the other hand, superior levels of certain indicators show the absolute and comparative advantages of farms of Natural Persons related to sustainable development. At the current stage of development the latter are associated with good eco-efficiency associated with Preservation of Quality of Surface and Ground Waters from contamination with nitrates and pesticides, Preservation of Air Quality and Quality of Eco-system Services, extent of implementation of Good Agricultural Practices, Preservation of Soil Organic Content, application of recommended Norms of Nitrogen Fertilization, good Adaptability to Market (prices, competition, demands, etc.), and Acceptable Working Conditions. 
There are significant variations in sustainability of Natural Persons depending on their size, production specialization, and ecological and geographical location (Figure 7).

Figure 7. Levels of Sustainability Index of Farms of Natural Persons of Different Kind and Location in Bulgaria

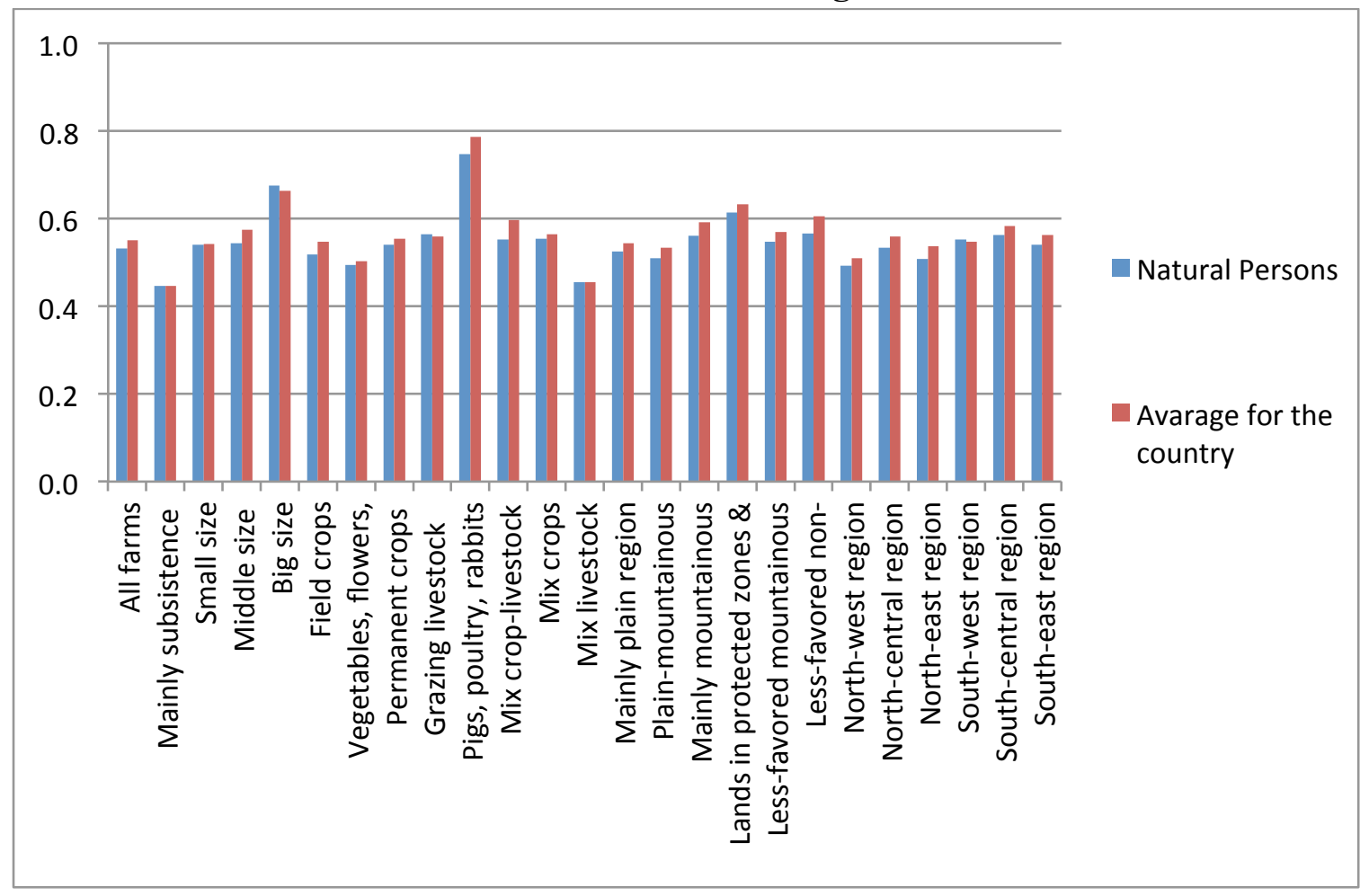

Source: survey with managers of farms, July 2016

With the best sustainability, within a good level, are holdings of Natural Persons with Big size, specialized in Pigs, Poultry and Rabbits, these with Lands in Protected Zones and Territories, and located in the South-Central Region of the country. At the same time, with a low sustainability are Natural Persons which are Predominately for Subsistency, those specialized in Mix-Livestock and in Vegetables, Flowers and Mushrooms, and located in the North-West Region of the country. According to the ecological location, the lowest, within a good level, is sustainability of Natural Persons situated in Plain-mountainous Regions of the country.

Holding of Natural Persons are the most numerous and to a great extent they (pre)determine the "average" sustainability level of farms in the country. Consequently, the level of integral sustainability of Natural Persons of different kind deviates insignificantly from the average sustainability levels of respective categories of farms in the country. Simultaneously, considerable variation of sustainability of Natural Persons depending on their kind indicates that the size, 
product specialization and location of these holdings are more important factors for their sustainability than their juridical status. ${ }^{3}$

The overall and partial sustainability levels of Natural Persons do not give a full picture about the state of all holdings since there is a great variation in the share of farms with different sustainability levels. Almost two-third of farms of Natural Persons in the country are with a good sustainability and only under $1 \%$ with a high sustainability (Figure 8 ). At the same time, more than a third of all Natural Persons (34\%) are with a low sustainability or unsustainable at all (5\%).

\section{Figure 8. Structure of Farms of Different Juridical Type with Unlike Sustainability Level (percent)}

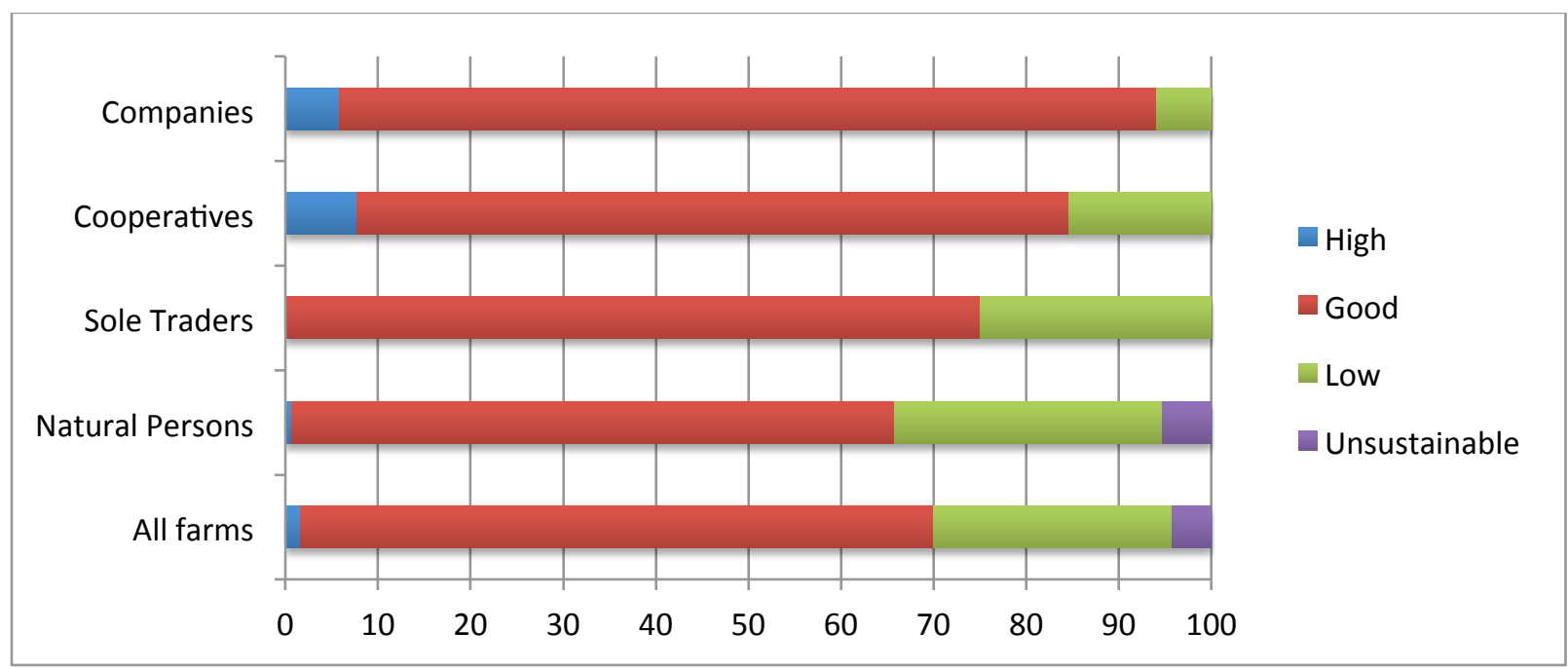

Source: survey with managers of farms, July 2016

Natural Persons are to a greater extent unsustainable comparing to other categories of farms in the country. The share of Natural Persons with a low sustainability is much bigger of portion of holdings with such level in other juridical types, as unsustainable are inclusively that group of enterprises. The greatest is the share of farms with a good and high sustainability in the group on Companies, followed by Cooperatives and Sole Traders, as every forth of Sole Traders is with a low sustainability level, similarly to $15 \%$ of Cooperatives, and $6 \%$ of Companies.

\footnotetext{
${ }^{3}$ That is also the case with certain type of firms - e.g. those with Big size for the sector, specialised in Grazing Livestock, etc. On the other hand, for Cooperatives, the specific juridicial (and governance) form is a critical factor deterniming sustainability level, rather that their belogning to a particular categogy of enterprises in the country (Bachev, 2017).
} 
Above figures demonstrate comparative advantages of other juridical (and governance) type of enterprises comparing with Natural Persons in regard to sustainable development. They confirm well-known trend for constant reduction in number and importance of Natural Persons in the structure of Bulgarian farming enterprises during last two decades (Bachev, 2010).

Analysis of structure of enterprise with different level of sustainability for each sustainability aspect gives important information about the long-term sustainability of Natural Persons and factors for its improvement. Our assessment shows that $45 \%$ of surveyed Natural Persons are with a low governance sustainability or managerially unsustainable (Figure 9). That means that comparative efficiency (potential) for governing supply of labor, land, finance, etc. and marketing of produce is lower than another feasible organization, and that adaptability to evolving environment is insufficient. Furthermore, $48 \%$ of all Natural Persons are with a low economic sustainability or unsustainable at all (each tenth one). 
Figure 9. Structure of Farms of Different Type with Unlike Level of Governance, Economic, Social and Environmental Sustainability (percent)

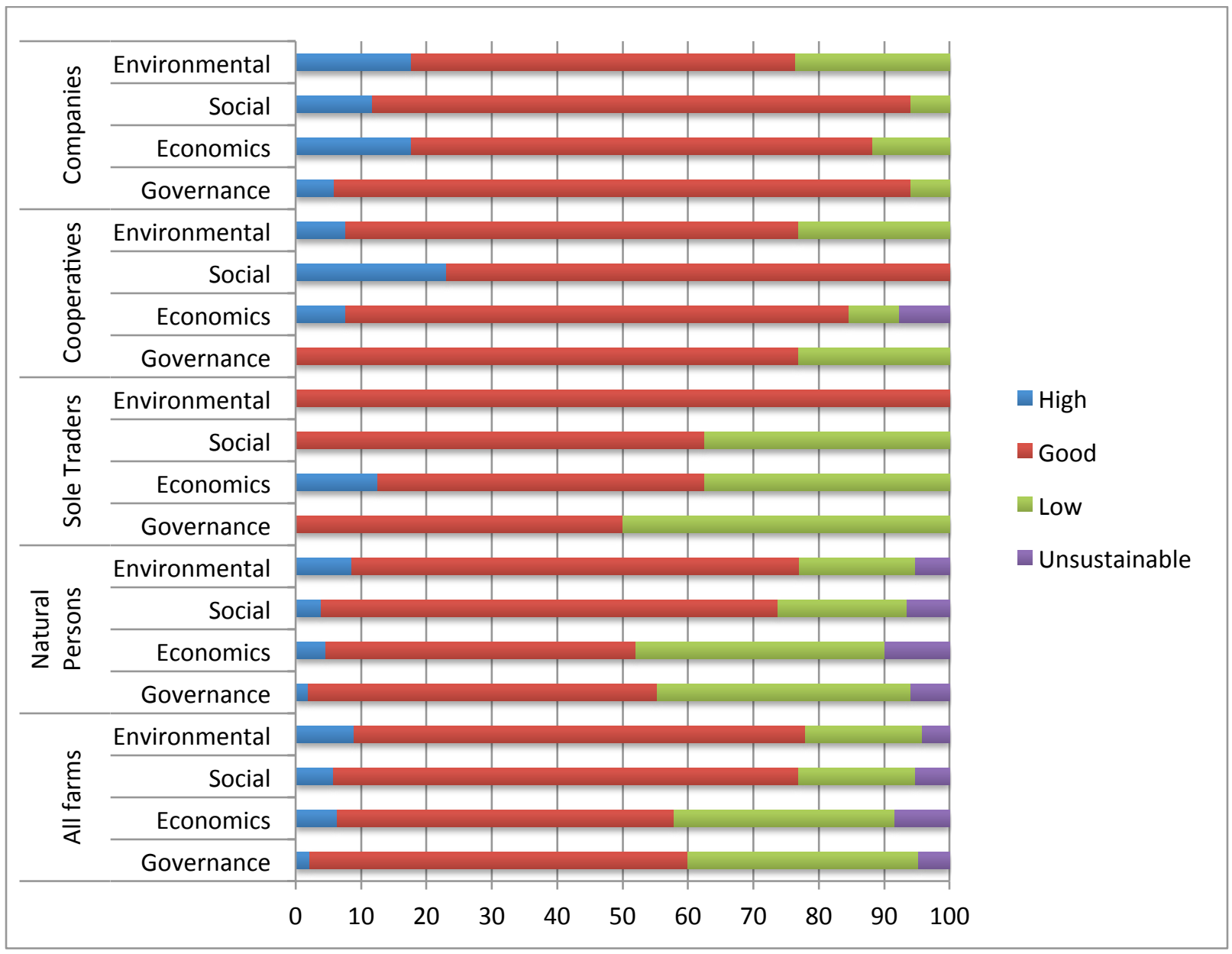

Source: survey with managers of farms, July 2016

All that means that a considerable part of farms of Natural Persons are with insufficient governance and economic sustainability for meeting contemporary socio-economic, market, institutional and environmental challenges, and they will cease to exists in near future unless adequate measures are undertaken (modernization, reorganization, public support, regulations, etc.) for their improving sustainability.

The portion of Natural Persons with inferior economic and governance sustainability is higher than Cooperatives and Companies, and in regard to economic sustainability exceeds Sole Traders as well. Thus, in near future management of resources of (a great portion of) economically and managerially low sustainable and unsustainable holdings of Natural Persons 
most likely will be transferred to organizations with higher comparative advantages (efficiency, sustainability) of another juridical type and/or Natural Persons with higher sustainability.

As far as the social aspect of sustainability is concerned, the structure is more favorable and the majority of farms of Natural Persons surveyed farms with a good or high social sustainability. Despite that, more than a quarter of holdings are with a low social sustainability or socially unsustainable. Only share of Sole Traders with inferior levels of social sustainability is bigger. That demonstrates that social efficiency of holdings of Natural Persons for farmers, communities and society and a whole do not correspond to contemporary requirements and standards. A good portion of these farms currently are with a low social sustainability or socially unsustainable, which compromises their overall middle and long-term sustainability. Therefore, effective measures have to be undertaken immediately to improve income, labor and living conditions of farmers and farm households as well as their importance for preservation of rural communities and traditions.

Environmental sustainability of the majority of farms of Natural Persons is good or superior, while a considerable portion is with a low sustainability (18\%) or even environmentally unsustainable (5\%). The share of these farms with inferior eco-efficiency is similar to those for Cooperatives and Companies, and gives a way only to Sole Traders. Nevertheless, above figures show, that eco-efficiency in a large number of Natural Persons in the country do not meet contemporary norms and standards for preservation of agricultural lands, waters, air, biodiversity, ecosystem services, and animal welfare. A good number of Bulgarian farms are with a low ecosustainability or environmentally unsustainable, which also compromises their overall long-term sustainability. Therefore, effective measures have to be undertaken to improve eco-efficiency in these groups through training, informing, stimulation, sanctions, etc.

There is also a significant differentiation in the share of farms with different level of sustainability for the major type of Natural Persons (Figure 10). All Natural Persons with Big size for the sector and specialized in Pigs, Poultry and Rabbits, and most of these in Mix Cops and Permanent Crops, and located in Non-mountainous Regions with Natural Handicaps and with Lands in Protected Zones and Territories are with a good (and a part with a high) sustainability. 
Figure 10. Structure of Natural Persons of Different Type with Unlike Sustainability Level in Bulgaria (percent)

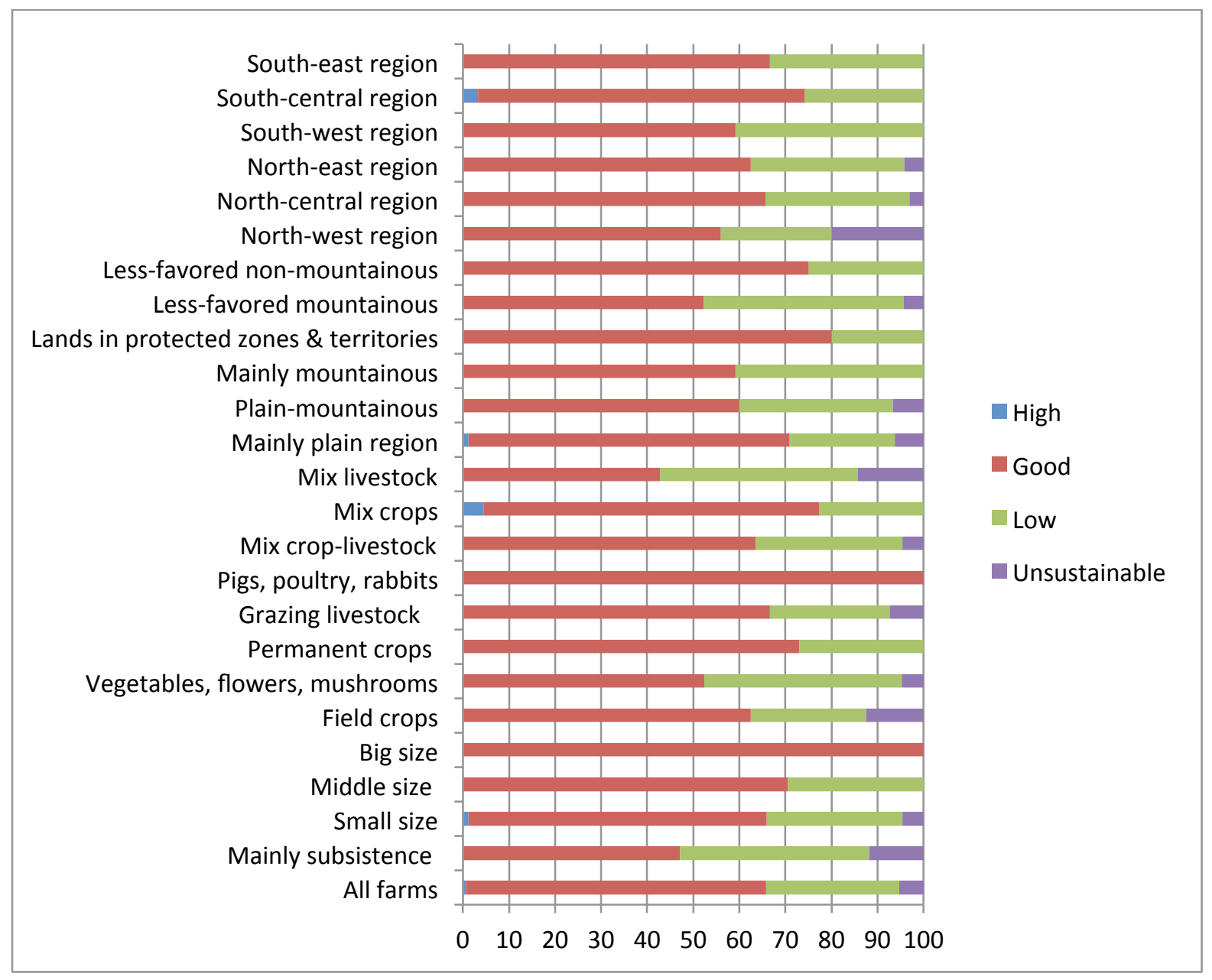

Source: survey with managers of farms, July 2016

On the other hand, majority of Natural Persons, which are Predominately for Subsistence and these with Mix Livestock are with low sustainability or unsustainable. The portion is also considerable of low sustainable or unsustainable Natural Persons in groups with Vegetables, Flowers and Mushrooms, Grazing Livestock, and Crop-Livestock specialization, those located in Mountainous Regions with Natural Handicaps, in Plain-Mountainous Regions, and in North-West and South-Wets Regions of the country.

Data for dispersion of farming enterprises of different type in groups with diverse level of sustainability has to be taken into account when forecast the number and importance of holdings of Natural Persons of each kind and location, as well as when modernize public (structural, 
sectorial, regional, environmental, etc.) policies for supporting agricultural producers of certain type, sub-sectors, eco-systems, and regions of the country.

\section{Conclusion}

Our survey includes "typical" and to a certain extent "sustainable" (perspective) farms of Natural Persons in Bulgaria, which means that sample sustainability level is higher than the real (average) for the country. Despite that undertaken first large-scale study on sustainability of these holdings let us make some important conclusions about the level of sustainability of enterprises, and recommendations for improving managerial and assessment practices.

Suggested holistic framework gives a possibility to assess, analyze and improve sustainability level of individual farms and enterprises of different type in general and for major aspects, principles, criteria and indicators of sustainability. The inclusion of a new "governance" dimension of farm sustainability let us evaluate its level more precisely. Furthermore, different degrees of aggregations allow assessment results to be effectively used at various decisionmaking levels - from lowest (individual or group of enterprises) to the highest (policy making). That approach has to be further discussed, experimented, improved and adapted to the specific conditions of operation and development of farming enterprises of different type and location, as well as special needs of decision-makers at various levels.

The overall sustainability of Natural Persons in the country is at a good level, with superior levels for environmental and social sustainability, close to the border with low level governance sustainability, and inferior economic sustainability. Furthermore, comparative sustainability of these holdings as a whole and for individual aspect is lower than the average sustainability of enterprises in the country and from the level of other juridical (governing) type.

There are also great variations in sustainability levels of farms of different kind and location. Besides, the share of Natural Persons with good and high sustainability is much smaller than other categories of enterprises. All that means that majority of Natural Persons do not have comparative advantages in relations to efficiency and sustainability, and in a middle term will cease to exist transferring management of resources into more-efficient and sustainable structures.

Having in mind the importance of such comprehensive assessments of levels and factors of sustainability of farms, and enormous benefits for farm management and agrarian policies, such studies are to be expended and their precision and representation increased. The latter 
require a close cooperation between all interests parties and participation of farmers, agrarian organizations, local and state authorities, interest groups, research institutes and experts, etc. Moreover, precision of estimates has to be improved and besides on assessments of managers to incorporate relevant information from field tests and surveys, statistical and other data, and expertise of professionals in the area.

\section{References:}

Andreoli, M. - V/ Tellarini (2000): Farm sustainability evaluation: methodology and practice, Agriculture, Ecosystems \& Environment, Vol. 77, Issues 1-2, 43-52.

Bachev, H. (2004): Efficiency of Agrarian Organizations. Farm Management and Rural Planning, 5, 135-150.

Bachev, H. (2005): Assessment of Sustainability of Bulgarian Farms. Proceedings, XIth Congress of the European Association of Agricultural Economists. Copenhagen: EAAE.

Bachev, H. (2010): Governance of Agrarian Sustainability. New York: Nova Science Publishers. Bachev, H. (2011): Efficiency of Economic Organizations and Public Policy Interventions in Agriculture, in L.Contreras (editor), Agricultural Policies: New Developments, New York: Nova Science, 55-86.

Bachev, H. (2013). Risk Management in Agri-food Sector. Contemporary Economics, 7 (1), 45 62.

Bachev, H (2016): A Framework for Assessing Sustainability of Farming Enterprises. Journal of Applied Economic Sciences, Vol XI, 1(39), 24-43.

Bachev, H. (2017): Sustainability Level of Bulgarian Farms. Bulgarian Journal of Agricultural Science, 1, 1-13.

Bachev, H. - Petters, A. (2005): Framework for Assessing Sustainability of Farms, in Farm Management and Rural Planning. No 6, 221-239.

Bachev, H. - Tsuji, M. (2001): Structures for Organization of Transactions in Bulgarian Agriculture. Journal of the Faculty of Agriculture of Kyushu University, 46 (1), 123-151.

Bachev, H. - Kagatsume, M. (2002): Restructuring of Bulgarian Agriculture, in Kagatsume at all. Agricultural Restructuring and Environmental Issues in Eastern Europe under the Transition Process, Graduate School of Agriculture, Kyoto University, Kyoto. 
Bachev, H. - Nanseki, T. (2008): Environmental Management in Bulgarian Agriculture - Risks, Modes, Major Challenges. Journal of the Faculty of Agriculture of Kyushu University, 53 (1), 363-373.

Bastianoni S. - N. Marchettini, - M. Panzieri, - E. Tiezzi (2001): Sustainability assessment of a farm in the Chianti area (Italy), Journal of Cleaner Production, Vol. 9, Issue 4, 365-373.

Brklacich, M. - Bryant, C. - Smith, B. (1991): Review and appraisal of concept of sustainable food production systems. Environmental Management, 15(1): 1-14.

Csaki, C. - Forgács, C. - Milczarek, D. - Wilkin, J. (Eds) (2008): Regional Outcome: Central and Eastern Europe. Restructuring market relations in food and agriculture of Central and Eastern Europe - Impacts upon small farmers. Budapest: Agroinform.

Davidova, S. (2014): Small and Semi-subsistence Farms in the EU: Significance and Development Paths, EuroChoices, Vol. 13, Issue 1, 5-9.

Diazabakana, A. - Latruffe, L. - Bockstaller, C. - Desjeux, Y. - Finn, J. - Kelly, E. - Ryan, M. Uthes, S. (2014): A Review of Farm Level Indictors of Sustainability with a Focus on CAP and FADN, FLINT

http://www.flint-fp7.eu/downloads/reports/FLINT\%20WP1\%20_D1_2.pdf

EC (2001): A Framework for Indicators for the Economic and Social Dimensions of Sustainable Agriculture and Rural Development. Brussels: European Commission.

FAO (2013): SAFA. Sustainability Assessment of Food and Agriculture systems indicators. Rome: FAO.

Fuentes, M. (2004): Farms Management Indicators Related to the Policy Dimension in the European Union, OECD Expert Meeting on Farm Management Indicators and the Environment, 8-12 March 2004, New Zealand

Häni, F. - Pintér, L. - Herren, H. (2006): Sustainable Agriculture. From Common Principles to Common Practice, Proceedings of the first Symposium of the International Forum on Assessing Sustainability in Agriculture (INFASA), March 16, 2006, Bern, Switzerland.

Hayati, D. - Ranjbar, Z. - Karami, E. (2010): Measuring Agricultural Sustainability, in E. Lichtfouse (Ed.), Biodiversity, Biofuels, Agroforestry and Conservation Agriculture, Sustainable Agriculture Reviews 5. Springer Science, 73-100.

MAF (2012): Agrarian paper. Sofia: Ministry of Agriculture and Food. 
OECD (2001): Environmental indicators for agriculture. Vol. 3: Methods and Results. Paris: OECD.

Rigby, D. - Woodhouse, P. - Young, T. - Burton, M. (2001): Constructing a farm level indicator of sustainable agricultural practice. Ecological Economics, Vol. 39, Issue 3, 463-478.

Sauvenier, X. - Valekx, J. - Van Cauwenbergh, N. - Wauters, E. - Bachev, H. - Biala, K. Peeters, A. (2005): Framework for Assessing Sustainability Levels in Belgium Agricultural Systems - SAFE. Brussels: Belgium Science Policy.

UN (2015). Paris Climate Change Conference, November-December 2015.

Williamson, O. (1996): The Mechanisms of Governance. New York: Oxford University Press. 